\title{
Effects of Hybrid Structure on Properties of Glass-Carbon Hybrid Fibers Composite
}

\author{
Yang Rui ${ }^{1,2, a}$, Liu Ye-yao ${ }^{1, b}$, Wang Gong-xi ${ }^{1, c}$ and Wu Zhuo-qi ${ }^{1, d}$ \\ ${ }^{1}$ College of Energy and Power Engineering, Lanzhou University of Technology, \\ Lanzhou, Gansu province, China \\ 2Wind Turbine Engineering and Technology Research Center of Gansu province, \\ Lanzhou University of Technology, Lanzhou, Gansu province, China \\ a562204233@qq.com, b2548777970@qq.com, c541503906@qq.com, d1257338756@qq.com
}

Keywords: hybrid structure; glass-carbon hybrid fibers; mechanical properties; dispersion Abstract. In order to investigate the influence of two kinds of hybrid structure (sandwich and interlaminated) on the properties of glass carbon hybrid fiber materials. We did the experiment with the pure glass fiber material as contrast object. In the case of the same relative volume of carbon fiber, the experimental study of the two hybrid modes laminates of the sandwich structure and interlaminated structure was carried out under tension, compression and bending load. The experimental results show that in the tensile and compressive properties, the sandwich structure can increase the elastic modulus, but the strength decreases. At the same time, the interlaminated structure can effectively improve the strength and elastic modulus. In bending properties, the sandwich structure show better performance than the interlaminated structure, while the sandwich structure with the carbon fibers surface can give full play to the advantages of both fibers.

\section{Introduction}

Glassy-carbon hybrid fiber composite refers to a new composite material formed by glass fiber and carbon fiber enhancing the same matrix material by some way. Carbon fiber is light in weight, high in tensile strength and modulus of elasticity, but low in elongation and expensive. Glass fiber has high elongation and low price ${ }^{[1-2]}$. Ultimately, this new composite can combine the strength and toughness of carbon and glass fibers, avoiding the high cost of carbon fiber and the high quality of glass fiber.

Hybrid effect refers to the phenomenon that the results deviate from the law of mixture after mixing different fibers. There are many influencing factors of hybrid effect ${ }^{[3]}$, such as hybrid materials, hybrid ratio, hybrid structure, mixed interface, fiber dispersion and so on. Hybrid structure is a very important influencing factors, and the different hybrid structure will also affect the number of mixed interfaces and the degree of dispersion. At present, the hybrid style of hybrid materials can be roughly divided into five types ${ }^{[4]}$ : Intraply hybrid composite (the same layer, two kinds of fibers laid evenly distributed in a certain proportion); Interply hybrid composite (two kinds of fibers laid in different layers according to a certain ratio); Sandwich hybrid composite (a fiber as the core, another fiber as the surface layer); Intraply / interply hybrid composite; Super hybrid composite material (composed of a variety of metal materials and a single composite). Since there is no mixed interface in the intraply hybrid structure and the dispersion can not be characterized, we do not do research here.

For the study of hybrid structures, Zhao ${ }^{[5]}$ and Sayer ${ }^{[6]}$ found that in the case of glass fiber as the surface layer, the impact resistance of glassy carbon hybrid fibers is the best. Park ${ }^{[7]}$ and Zhang ${ }^{[8]}$ experimentally studied the effect of sandwich structure on the bending properties of Kevlar / UHMWPEF and CF / UHMWPEF hybrid fibers: Bending properties will be good when low elongation fibers are on the curved upper surface. He et al. ${ }^{[9-11]}$ studied the effect of hybrid ratio, structural adhesive, etc. on the properties of glassy carbon hybrid fibers under the interlaminated structure. In the literature, there are many studies on the hybrid ratio of sandwich structure and interlaminated structure. However, there are few documents about the two kinds of hybrid structures 
and their influence mechanism. In this paper, the effect of interlaminated structure and sandwich structure on the tensile, compressive and bending properties of glassy carbon hybrid composites under the same lay-up ratio and same hybrid ratio is studied and the failure mechanism is analyzed.

\section{Experimental materials and methods}

Materials and samples. Glass-carbon hybrid fiber composite materials used in the experiment are hand-made. Its raw materials for TC-191DC unsaturated polyester resin, EWR200 / 02 E-glass fiber, SKO carbon fiber (elongation 1.5\%), V388 curing agent, CN/3800600 accelerator. In the experiment, the resin was formulated with $0.4 \%$ of curing agent and $0.4 \%$ of accelerator. The curing time exceeded $100 \mathrm{~min}$ and the curing temperature was $30^{\circ} \mathrm{C}$. According to the requirements to produce samples,and cut and grind the samples after cured at room temperature. All samples were laid 20 layers, and the form is $\left[0_{5} / 90_{5}\right]_{\mathrm{s}}$. The specific scheme is shown in Table 1 , wherein $\mathrm{G}$ and $\mathrm{C}$ represent glass fiber layers and carbon fiber layers, s represents a symmetrical ply, the number of mixed interfaces represents the number of interfaces between the two fiber plies, and the dispersion coefficient $\varphi$ represents the dispersion of the hybrid materials. The formula of dispersion coefficient $^{[12]}$ is

$$
\varphi=1-\left(H_{1}^{2}+H_{2}^{2}+H_{3}^{2}+\cdots \cdots \cdot \cdot\right) / H^{2} .
$$

In the formula, $H$ - Mixed board total thickness $(m m), H=H_{1}+H_{2}+H_{3}+\cdots \cdots ; H_{1}, H_{2}$, $\mathrm{H}_{3}$ —Continuous thickness of the same fiber $(\mathrm{mm})$. Sample size is shown in Table 2. Each sample has 5 groups (size error $\pm 0.2 \mathrm{~mm}$ ). The experimental data take the average of valid data in five sets of data.

Table 1 sample ply schedule

\begin{tabular}{ccccc}
\hline Sample & $\begin{array}{c}\text { Layers } \\
\text { parameters }\end{array}$ & $\begin{array}{c}\text { Carbon fiber relative } \\
\text { volume content }\end{array}$ & $\begin{array}{c}\text { Mixed interface } \\
\text { number }\end{array}$ & $\begin{array}{c}\text { Dispersion } \\
\text { coefficient } \varphi\end{array}$ \\
\hline A & $\mathrm{G}_{20}$ & 0 & 0 & 0 \\
B (sandwich) & {$\left[\mathrm{G}_{7} \mathrm{C}_{3}\right]_{\mathrm{s}}$} & 0.41 & 2 & 0.66 \\
$\mathrm{C}$ (interlaminated $)$ & {$\left[\mathrm{G}_{4}\left(\mathrm{C}_{1} \mathrm{G}_{1}\right)_{3}\right]_{\mathrm{s}}$} & 0.41 & 12 & 0.92 \\
\hline
\end{tabular}

Table 2 sample size

\begin{tabular}{cccccccc}
\hline & $\begin{array}{c}\text { Length } \\
{[\mathrm{mm}]}\end{array}$ & $\begin{array}{c}\text { Width } \\
{[\mathrm{mm}]}\end{array}$ & $\begin{array}{c}\text { Thickness } \\
{[\mathrm{mm}]}\end{array}$ & $\begin{array}{c}\text { Height } \\
{[\mathrm{mm}]}\end{array}$ & $\begin{array}{c}\text { The gauge width } \\
{[\mathrm{mm}]}\end{array}$ & $\begin{array}{c}\text { The gauge length } \\
{[\mathrm{mm}]}\end{array}$ \\
\hline Sample & A、B、C & A、B、C & A & B、C & A、B、C & A、B、C & A、B、C \\
$\begin{array}{c}\text { Stretch } \\
\text { (dumbbell shape) }\end{array}$ & 180 & 20 & 4 & 4.8 & $/$ & 10 & 50 \\
Compression & $/$ & 14 & 4 & 4.8 & 18 & $/$ & $/$ \\
Bending & 180 & 15 & 4 & 4.8 & $/$ & $/$ & $/$ \\
\hline
\end{tabular}

Sample testing and data acquisition. Tensile, compression, bending(three-point bending) test use computer-controlled electronic universal testing machine 100D. The experiment is in line with GB/T 1446 standards. At the start of the experiment, the control loading rate was $2 \mathrm{~mm} / \mathrm{s}$ and the steady loading rate was $5 \mathrm{~mm} / \mathrm{s}$. The sample was continuously loaded until the sample was damaged. After the sample is destroyed, the load-deformation curve is collected and saved by the test data system automatically. 


\section{Results and analysis}

Effect of Hybrid Structure on Tensile Properties. The stiffness of the composite material is mainly reflected in the tensile stiffness of the fiber ${ }^{[13]}$. The tensile properties of carbon fiber is much higher than that of glass fiber. Therefore, the influence of the hybrid structure on the tensile properties of glassy carbon hybrid fibers is the most important reference factor. Figure 1 shows the load -deformation curve of the tensile test. Be seen from Figure 1, the sandwich structure sample (B) was once broken and the interlaminated structure sample (C) undergone secondary fractures. As shown in Fig. 2, the carbon fiber fracture in the middle of the sandwich structure sample has smooth fracture, shown as complete break. However, part of the glass fiber on the surface is pulled out. It can be seen that the fiber breakage occurred first in the low elongation carbon fiber during the tensile loading process. The carbon fiber in the sandwich structure specimen is too concentrated. When a fiber breakage occurs in the center, the fractional fissure will rapidly spread to all the carbon fibers and spread to the outer glass fiber. Due to the rapid diffusion of cracks and ever-reduced loaded area, glass fibers can not stand alone. Finally, the crack runs through the entire sample and the sample breaks. In the interlaminated structure specimens, the fiber fractures had layer phenomenon and a large amount of fibers (including glass fibers and carbon fibers) pulled out. Due to the uniform propagation of the cracks, it is known that the pre-fractured carbon fibers are surrounded by the glass fibers on both sides. Because of the good elongation of glass fiber, the crack is effectively restrained and extended along the mixed interface. With the continuous improvement of load, the glass fiber will fracture when the stress on the crack exceeding the endurance limit of glass fiber. Then cracks spread to other layers. When all the glass fibers break, the material is completely destroyed. Fracture analysis shows that interlaminated structure can make better use of the advantages of high elongation of glass fiber than sandwich structure. The interlaminated structure can improve the toughness and fiber strength of carbon fiber.

\section{Load - deformation curve}

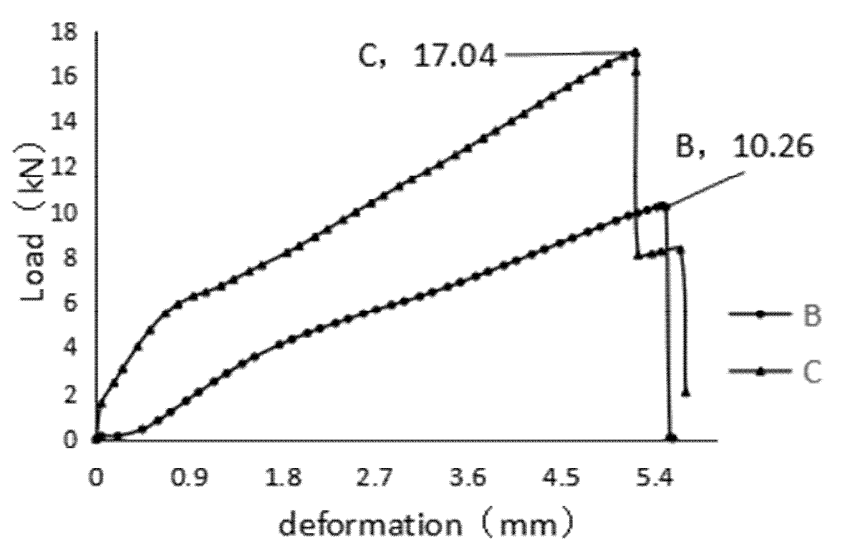

Fig.1 Load - deformation curve

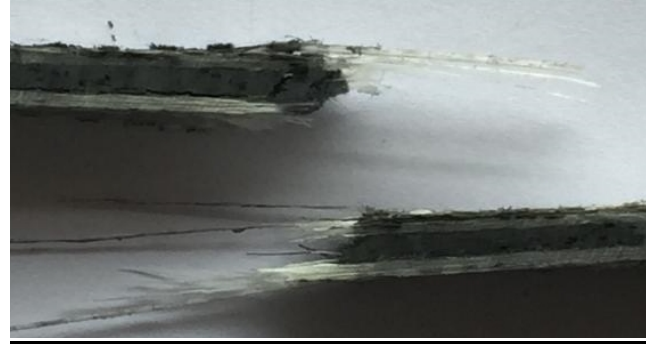

(a) B tensile fracture

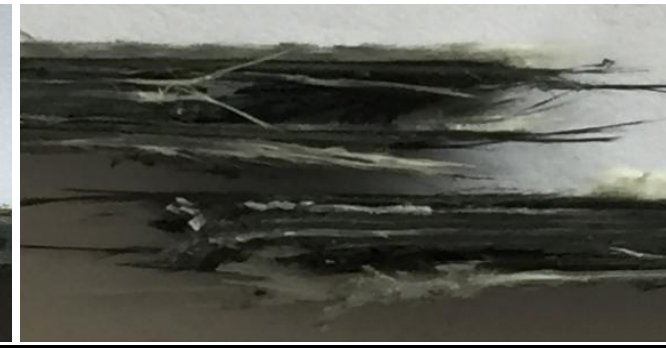

(b) C tensile fracture

Fig.2 B、C tensile fracture 
Tensile test data are shown in Table 3. The tensile strength of the sandwich structure specimen was lower than single glass fiber specimen, but its tensile modulus was higher. The tensile strength and tensile modulus of the interlaminated structure specimens were both higher than single glass fiber specimen and sandwich structure specimen. Strength analysis: In the sandwich structure samples, the fiber dispersion is 0.66 and the number of mixed interfaces is 2. Each carbon fiber layer and each glass fiber layer are too concentrated. The same kind of fiber layers connected closely and affect each other, so it can be seen as one. In the continuous loading of the tensile load, because the two fibers entirety on both sides of the mixed interface are greatly different, the interface is not closely bonded and leads to material instability. Finally, the tensile strength of the sandwich structure is lower than the tensile strength of the single glass fiber. In the interlaminated structure samples, the number of mixed interfaces is 6 times size of the sandwich structure and the degree of fiber dispersion is 1.4 times size of the sandwich structure. There are very few layers of fibers on each side of the mixed interface. In the tensile loading process, the interface has good adhesion which can maintain a good balance. Finally, the tensile strength of the interlaminated structure is greatly increased. Modulus analysis: Carbon fiber as the main load in the process of loading, its stiffness is much larger than the glass fiber. Therefore, compared with the single glass fiber sample, the tensile modulus of hybrid fiber samples have different degrees of improvement. The sandwich structure and the interlaminated structure were increased by $1.6 \%$ and $42.7 \%$ respectively. Combined the tensile strength and tensile modulus, the interlaminated structure can better enhance the tensile properties of the composite than the sandwich structure.

Table 3 tensile test results

\begin{tabular}{ccccc}
\hline Sample & $\begin{array}{c}\text { Tensile } \\
\text { stress }[k N]\end{array}$ & $\begin{array}{c}\text { Tensile } \\
\text { strength }[\mathrm{MPa}]\end{array}$ & $\begin{array}{c}\text { Elongation at } \\
\text { break[\%] }\end{array}$ & $\begin{array}{c}\text { Tensile elastic } \\
\text { modulus[GPa] }\end{array}$ \\
\hline A & 12.61 & 315.25 & 2.46 & 12.82 \\
B (sandwich) & 10.26 & 213.75 & 1.64 & 13.03 \\
C (interlaminated) & 17.04 & 355 & 1.94 & 18.3 \\
\hline
\end{tabular}

Effect of Hybrid Structure on Compression and Bending Properties. As shown in Table 4, similar to the situation of tensile property, the compressive strength of the sandwich structure specimen was lower than the single glass fiber specimen, but its compression modulus was higher. The compressive strength and compressive elastic modulus of the interlaminated structure specimens were both higher than the single glass fiber specimen and the sandwich structure specimen. From Figure 3, it is easier to see the difference between the sandwich structure and the interlaminated structure. The mixed interface of the sandwich structure is obviously degummed and split, and the crack propagates along the mixed interface. The interlaminated structure shows average delamination damage and the fracture cracks penetrated through multiple layers, so the confounding effect is more obvious. The result is that the compression performance of the interlaminated structure is better than the sandwich structure.

Table 4 compressed, bending test results

\begin{tabular}{ccccc}
\hline Sample & $\begin{array}{c}\text { compressive } \\
\text { strength }[\mathrm{MPa}]\end{array}$ & $\begin{array}{c}\text { compression elastic } \\
\text { modulus }[\mathrm{GPa}]\end{array}$ & $\begin{array}{c}\text { bending strength } \\
{[\mathrm{MPa}]}\end{array}$ & $\begin{array}{c}\text { flexural modulus } \\
{[\mathrm{GPa}]}\end{array}$ \\
\hline A & 46.96 & 2.11 & 218.75 & 25.39 \\
B (sandwich) & 28.87 & 2.60 & 147.57 & 17.79 \\
C (interlaminated) & 48.21 & 2.89 & 138.89 & 16.57 \\
\hline
\end{tabular}

The result of bending experiment is totally different from tensile and compression. Compared with the single glass fiber, the bending strength of the sandwich structure and the interlaminated structure decreased by $32.53 \%$ and $36.51 \%$ respectively and the bending modulus decreased by $29.93 \%$ and 
$34.73 \%$ respectively. In theory ${ }^{[14]}$, the single glass fiber has high bending strength and low modulus, while the single carbon fiber is the opposite. The bending strength of hybrid fibers should increase with the increase of relative volume content of carbon fibers, but always lower than the single glass fibers, and the modulus should always be higher than the single glass fibers. However, the bending strength and flexural modulus of hybrid fibers both decreased in the experiment. Under the bending loads, the ideal situation is that the outer layer begins to break and the outer crack spreads into the middle layer and eventually destroys completely ${ }^{[15]}$. In the experiment, the center-located carbon fibers in the sandwich structure and the interlaminated structure are fractured first due to the lower elongation (as Figure 4). Than fibers in the outer layers lose support and the specimen fails. Therefore, in the bending experiment, the carbon fiber with lower elongation should be placed on the surface layer. This can reflect the high modulus of carbon fiber performance. In addition, the decrease in bending strength and modulus of the sandwich structure is significantly lower than the interlaminated structure. This is due to the fact that the carbon fibers in the center of the sandwich structure are grouped together and have a better carrying capacity than the single carbon fiber layer in the interlaminated structure. To sum up, the bending properties of hybrid materials with carbon fibers in the surface layer are better. At the same time, the bending properties of the sandwich structure are better than the interlaminated ones.

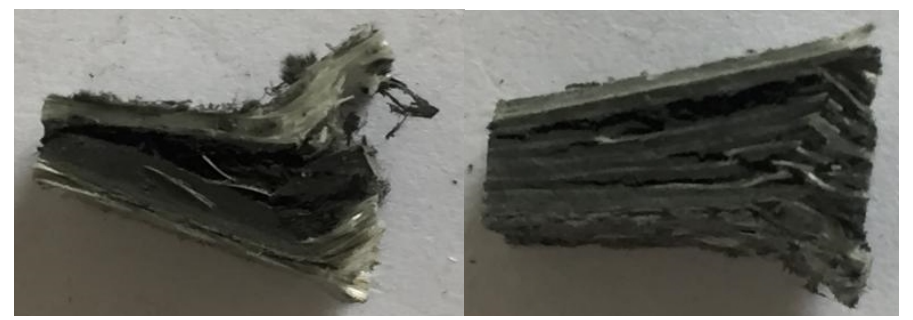

(a) B compressed fracture (b) C compressed fracture Fig.3 B、C compressed fracture

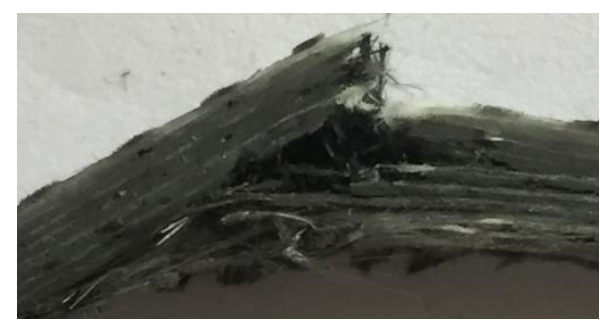

Fig.4 $\mathrm{C}$ bending fracture

\section{Conclusions}

Under tensile and compressive properties, the interlaminated structure has better performance than the sandwich structure. The sandwich structure has a higher modulus than single fiber, but the strength decreases. The interlaminated structure is both higher in strength and modulus than the sandwich structure and single glass fiber.

Under bending properties, the sandwich structure performs better than the interlaminated structure. The bending strength and flexural modulus of the sandwich structure are both higher than the interlaminated structure. In the case of bending, it should use sandwich structure with low elongation carbon fiber on surface and high elongation glass fiber in middle. This not only reflects the high bending strength of glass fiber, but also can take advantage of the high flexural modulus of carbon fiber.

The main difference between the sandwich structure and the interlaminated structure is the difference in the number of mixed interfaces and the degree of fiber dispersion. This leads to different failure modes between the sandwich structure and the interlaminated structure. In the end, there are different effects. Carbon fibers are highly concentrated at low mixed interfaces numbers and fiber dispersion. Tensile and compression experiments showed that the carbon fiber begin to fracture, leading to material instability and ultimately completely destroyed. Bending test showed that the carrying capacity of carbon fiber increased. At high mixed interfaces number and fiber dispersion, the carbon fiber layers are single and dispersed. Tensile and compression experiments showed that carbon fiber has better adhesion and sample occur interlaminar fracture which taking the advantages of each fiber better. Bending experiments showed that the core layer is too weak, so the material failed earlier. 


\section{Acknowledgements}

This work was financially supported by the National Special Project for International Scientific and Technological Cooperation (2014DFR60990).

\section{References}

[1] Hosny A, Shaheen H, Abdelrahman A, et al. Performance of reinforced concrete beams strengthened by hybrid FRP laminates[J]. Cement \& Concrete Composites, 2006, 28(10):906-913.

[2] Wu Z, Kim Y J, Diab H, et al. Technical Papers: Recent Developments in Long-Term Performance of FRP Composites and FRP-Concrete Interface[J]. Advances in Structural Engineering, 2010, 13(5):891-903.

[3] Manders P W, Bader M G. The strength of hybrid glass/carbon fibre composites. Journal of Materials Science, 1981, 16(8): 2233-2245.

[4] Xu Huanhuan. Tensile mechanical properties of glass-carbon hybrid fiber composites[D]. Nanjing University of Aeronautics and Astronautics, 2014.

[5] Zhao Shicheng, Wang Zhenqing, Guo Jianming, et al. Effect of hybrid structure on low speed impact properties of $\mathrm{CF} / \mathrm{GF} /$ epoxy hybrid composites $[\mathrm{J}]$. Journal of Harbin Engineering University, 2015, 36 (11): 1476-1480.

[6] Sayer M. An Experimental Investigation on the Impact Behavior of Hybrid Composite Plates[J]. Composite Structures, 2010, 92(5):1256-1262.

[7] Park R, Jang J. Stacking sequence effect of aramid - UHMPE hybrid composites by flexural test method : MATERIAL PROPERTIES[J]. Polymer Testing, 1998, 16(6):549-562.

[8] Zhang yongbin, Shi Junhu, Wang Li. The influence of hybrid structure on the mechanical properties of CF/UHMWPEF composites [J]. fiber reinforced plastics / composites, 2005 (2): 17-19.

[9] He Xiaobing, Cao Yong, et al. Ultimate tensile properties of GFRP/CFRP interlaminated hybrid fiber composites $[\mathrm{J}]$. Journal of Chongqing Jiaotong University (NATURAL SCIENCE EDITION), 2013, 32 (6): 1153-1156.

[10] Li Chen, Xu Huanhuan, Gu Xingjin. The tensile strength prediction of hybrid composite layer[J]. Journal of composite materials, 2017, 34 (4): 795-800.

[11] He X B, Yan B, Gu J Y, et al. Crack-arresting and Strengthening Mechanism of Hybrid Fiber Reinforced Polymer Sheets in Strengthening of Reinforced Concrete Beams[J]. Journal of Engineering Science \& Technology Review, 2013, 6(2):134-138.

[12] Tian Yuefei, Cai Jiangyong, Wang Shuqin. Calculation of hybrid effects in hybrid FRP composites [J]. 2009.

[13] B.C. Hoth, A.A. Beck. Principles and applications of composite materials [M]. Science Press, 1992.

[14] Li Jiaju, Mai kancheng, Zeng Hanmin. Flexural and impact properties of C/G hybrid reinforced polysulfone and its blends with sandwich panels[J]. Journal of composite materials, 1989, 6 (1): 14-20.

[15] Yang Guangsong. Damage mechanics and damage of composite materials [M]. National Defence Industry Press, 1995. 